\title{
EUCALIPTO E CAPIM ELEFANTE: CARACTERÍSTICAS E POTENCIAL PRODUTIVO DE BIOMASSA
}

\section{EUCALYPTUS AND ELEPHANT GRASS: CHARACTERISTIC AND PRODUCTIVE POTENTIAL OF BIOMASS}

\author{
Evane da Silva, IF Sul de Minas Gerais - Campus Muzambinho, evane@eafmuz.gov.br. \\ DSc. Carlos Roberto Rocha, Universidade Federal de Itajubá, UNIFEI, carrobro@gmail.com
}

\section{RESUMO}

Biomassa é a matéria orgânica utilizada na produção de energia. Dentre as vantagens do uso da biomassa está, principalmente, a sustentabilidade, pelo fato de ser renovável, permitir o reaproveitamento de resíduos, não contribuindo para o efeito estufa, com o gás carbônico $\left(\mathrm{CO}_{2}\right)$, já que o mesmo é absorvido através da fotossíntese, o que não ocorre em outras fontes de energia como o petróleo ou o carvão, além disso, apresenta um baixo custo de produção. A biomassa se destaca, ainda, pelo seu potencial energético e pelas facilidades de armazenamento e transporte. Em vários países, a biomassa é considerada uma importante fonte de energia, principalmente em áreas rurais, a utilização da biomassa é, por vezes, a forma mais barata de produzir eletricidade ou ar quente para secagem de produtos agrícolas. $\mathrm{O}$ artigo descreve a importância do uso da biomassa como fonte energética e discute as características e potencial produtivo de biomassa do capim elefante e do eucalipto. Após a revisão de literatura foi possível identificar que o capim elefante pode ser mais eficiente e viável do que o eucalipto na produção de energia, visto que apresenta uma produtividade mais elevada (60 t/ha/ ano de massa seca); menor ciclo produtivo ( 2 a 4 cortes ao ano); é capaz de enriquecer naturalmente o solo; conservar os mananciais; pode ser produzido com a presença de animais; apresenta grande capacidade de captar $\mathrm{CO}_{2}$ devido ao seu elevado crescimento; e por fim ainda tem um alto teor de fibra que caracteriza um grande potencial energético e biomassa.

Palavras-chave: biomassa; eucalipto; capim elefante.

\section{ABSTRACT}

Biomass is the organic matter used in energy production. Among the benefits of using biomass is, primarily, the sustainability, by being renewing, to allow the recycle of the leftovers, not contributing for greenhouse effect, with the carbon dioxide $\left(\mathrm{CO}_{2}\right)$, and this one is absorbed by photosynthesis, which doesn't happens with others energy sources like petroleum and charcoal, besides, presents low production cost. The biomass stands out by its energy potential and its facility of storage and transportation. In several countries, the biomass is considered an important source of energy, mainly in rural areas, the biomass use is, many times, the cheapest way to produce electricity and hot air to dry agricultural products. The article describes the matter of biomass use as energy source and debates the characteristic and productive potential of biomass of elephant grass and eucalyptus. After the review of the literature was possible to identify that the elephant grass can be more efficient and viable than the eucalyptus in energy production, because it presents higher productivity $(60 \mathrm{t} / \mathrm{hec} / \mathrm{year}$ of dried mass); less productive cycle (2/4 cuts per year); is capable to naturally enrich the ground; maintain the fountainhead; can be produced with animal presence; presents large capacity to collect carbon dioxide $\left(\mathrm{CO}_{2}\right)$ overdue its elevated growth; and lastly it still has a high fiber import which characterize a great 
potential of energy and biomass.

Key words: biomass; eucalyptus; elephant grass.

\section{INTRODUÇÃO}

Atualmente a obtenção de lucro e o desenvolvimento a qualquer custo apresentam-se em permanente embate com a preocupação e a necessidade pela preservação dos recursos naturais. É neste ponto que se torna importante evitar os radicalismos, tanto consumista (extrativista) como ambientalista, tornando possível a utilização dos recursos naturais de maneira a atender as necessidades da sociedade, minimizando os danos causados ao meio ambiente (GUARDABASSI, 2006).

Com a industrialização, cada vez mais, dependemos da geração de energia, e esta obrigatoriamente deverá ser advinda de fontes sustentáveis, como por exemplo, da biomassa que oferece grandes vantagens energéticas, ambientais e econômicas. Além de ser uma fonte de energia renovável, também não emitem óxidos de enxofre, responsáveis pelas chuvas ácidas e não contribui para o aumento do efeito estufa, já que o $\mathrm{CO}_{2}$ emitido é novamente absorvido durante a fotossíntese das plantas (SALOMON, 2007).

Dentre as diversas biomassas tem-se o capim elefante (Pennisetum purpureum Schum.) que é considerado uma espécie de alta eficiência fotossintética (metabolismo C4). Isto resulta numa grande capacidade de acumulação de matéria seca, possuindo também características qualitativas que o credenciam a ser estudado para a produção de energia, como por exemplo, um percentual de fibra elevado, semelhante à cana-de-açúcar (QUESADA et al., 2004).

Outra biomassa muito utilizada e estudada é o eucalipto, que também ajuda na captura e na retenção carbono, além de produzir energia. Sua fonte de biomassa florestal é estimada em até 60 tha $^{-1}$ ano $^{-1}$ e ainda apresenta uma boa adaptação a solos com baixa fertilidade e déficit hídrico (OLIVEIRA NETO et al., 2003; PEREIRA et al., 2004)
Na busca por fontes renováveis de energia e uso sustentável das biomassas evidenciadas no contexto atual, este artigo irá descrever a importância do uso da biomassa como fonte energética e discutir as características e potencial produtivo de biomassa do capim elefante e do eucalipto.

\section{CONCEITOS E DEFINIÇÕES DE BIOMASSA}

Há várias definições para o termo "biomassa", por exemplo, Landim e seus colaboradores (2007), consideram como sendo biomassa energética toda a matéria orgânica capaz de, ao ser queimada, decomposta ou reciclada, gerar alguma forma de energia, direta ou indiretamente. Desse modo, lenha, rejeitos animais e dejetos humanos, resíduos agrícolas e resíduos urbanos de origem orgânica podem ser utilizados como combustível através da biodigestão ou outros processos tais como: pirólise, hidrólise, gaseificação ou queima direta.

O termo biomassa engloba, portanto, a matéria vegetal da fotossíntese e os seus derivados. Estes materiais contêm energia química proveniente da transformação energética da radiação solar (figura 1). Essa energia química pode ser liberada diretamente por combustão ou convertida através de algum processo em outras fontes energéticas mais adequadas, para um fim qualquer desejado (NOGUEIRA; LORA, 2003).

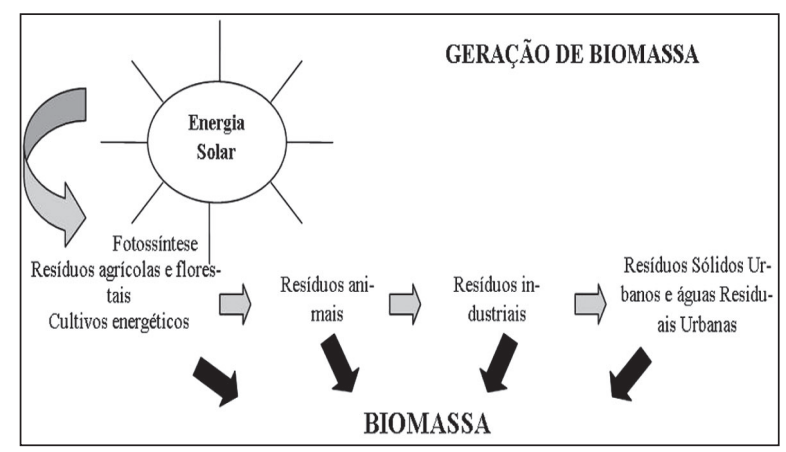

FIGURA 1 - Processo de produção de biomassa Fonte: Salomon (2007). 
Estima-se que existam dois trilhões de toneladas de biomassa no globo terrestre ou cerca de 400 toneladas por pessoa, o que, em termos energéticos, corresponde a oito vezes o consumo anual mundial de energia primária (produtos energéticos providos pela natureza na sua forma direta, como o petróleo, gás natural, carvão mineral, minério de urânio, lenha e outros), segundo Bubu (2004).

\section{A BIOMASSA COMO UMA FONTE DE ENERGIA RENOVÁVEL}

Nos países em desenvolvimento, a biomassa já é considerada uma importante fonte de energia. Principalmente em áreas rurais, a utilização da biomassa é, por vezes, a forma mais barata de produzir eletricidade ou ar quente para secagem de produtos agrícolas (SILVA, CARDOSO SOBRINHO, SAIKI, 2004).

Historicamente, uma das primeiras utilizações da biomassa, pelo homem para obtenção de energia, foi o fogo para cozimento e iluminação. O domínio do fogo permitiu ao homem a exploração dos metais. A madeira foi por muito tempo a principal fonte energética para a cocção, siderurgia e cerâmica (ROSTAND, 2007).

Ainda, de acordo com Anderson e Fergusson (2006) e Rostand (2007), com o aparecimento da máquina a vapor, a biomassa passou a ter aplicação para obtenção de energia mecânica na indústria e nos transportes. Mesmo com o início da exploração dos combustíveis fósseis, carvão mineral e petróleo, a lenha continuou desempenhando importante papel energético, principalmente nos países tropicais.

Alémdeserumafontedeenergia renovável, outra vantagem da utilização da biomassa em substituição aos combustíveis fósseis é o fato de desta gerar uma menor poluição atmosfera global e localizada, estabilidade do ciclo de carbono e maior emprego de mão de obra, além de apresentar uma alta densidade energética, facilidades de armazenamento, conversão e transporte (ROSTAND, 2007).

\section{VIABILIDADE DA UTILIZAÇÃO DE BIOMASSAS NO BRASIL}

Atualmente o Brasil encontra-se em situação privilegiada no que se refere a suas fontes primárias de oferta e energia. Verificase que a maioria da energia consumida no país é proveniente de fontes renováveis de energia (hidroeletricidade, biomassa em forma de lenha e derivados da madeira, como serragem, carvão vegetal, derivados da cana-de-açúcar e outras (GRAUER; KAWANO, 2001).

O Balanço Energético Nacional (MME, 2005) relata que no ano de 2002 as fontes renováveis foram responsáveis por $40 \%$ da produção de energia primária no Brasil, como mostra a figura 2 .

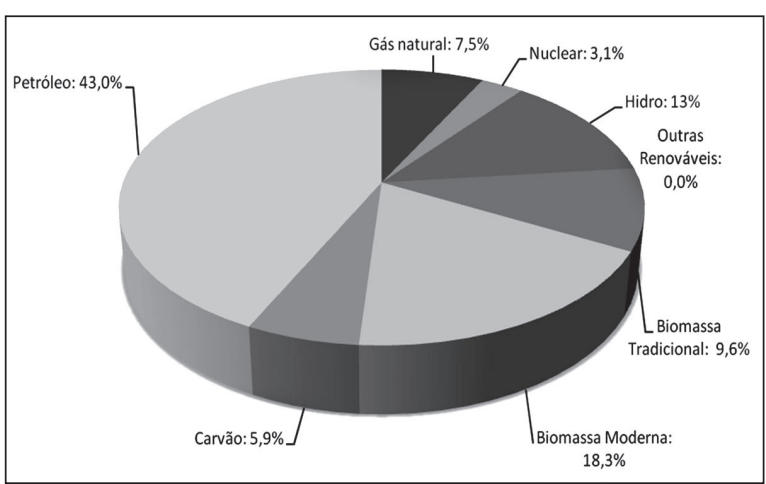

FIGURA 2 - Oferta de Energia Primária no Brasil, 2002

Fonte: Ministério de Minas e Energia (2005)

\section{CARACTERIZAÇÃO DO EUCALIPTO COMO FONTE DE BIOMASSA}

O gênero Eucalyptus abrange um grupo de plantas com mais de 600 espécies. Sua copa geralmente é rala e alongada e o tronco quase sempre retilíneo e cilíndrico, com casca ou muito lisa ou muito áspera e fissurada dependendo da espécie (BERTOLA, 2007).

Segundo Kronka et al. (2003) os plantios de florestas comerciais no Brasil cobrem uma área de 4,8 milhões de hectares. No Estado de São Paulo 
são 770 mil hectares de plantios ( $3,1 \%$ da área). Desse montante, o eucalipto responde por $79,4 \%$, o pinus com $20,6 \%$ e outras madeiras com $2 \%$.

Em relação às características do eucalipto tem-se ainda que considerar à composição química da madeira, pois a presença de um mais alto teor de substâncias de natureza aromática tais como, extrativos e lignina, dá como conseqüência um carvão com maior densidade e mais resistente em termos de propriedades físico-mecânicas, além de apresentarem um maior poder calorífico (BRITO; BARRICHELO, 1977).

\section{PRODUTIVIDADE DO EUCALIPTO}

Algumas espécies do gênero Eucalyptus apresentam um crescimento muito rápido, no início mais de 3 metros/ano (CATHARINO, 2007).

Osolo, e oclimasão fatores que influenciam diretamente na produção do eucalipto. Nosso clima contribui para que o Brasil destaque-se no cenário mundial com uma das mais altas taxas de produtividade na silvicultura, atingindo entre 40 e 50 metros cúbicos $\left(\mathrm{m}^{3}\right)$ de madeira por hectare ao ano, mais de 10 vezes superior à observada em países de clima temperado (OLIVEIRA JR, SEIXAS, 2006; RODRIGUEZ, BUENO, RODRIGUES, 1997).

A idade ótima de corte de um talhão florestal, independentemente dos demais, pode ser definida mais especificamente quando são utilizados os termos volumétricos e/ou econômicos. Rodriguez, Bueno e Rodrigues, em 1997, constataram que a idade ótima de corte, utilizando as medidas volumétricas, apresentase aos 6 anos, enquanto que ao se considerar os valores econômicos a idade ótima é 7 anos.

Não somente a taxa de crescimento fazse importante ao analisarmos às facetas do eucalipto, mas a produção de biomassa também é muito relevante. Baseado no balanço de radiação local como variável de predição do potencial líquido de fotossíntese, Pereira, Nova e Moreira (2004) relatam que a estimativa da produtividade máxima em biomassa florestal em até $60 \mathrm{t} \mathrm{ha}^{-1}$ ano $^{-1}$ na latitude de $60^{\circ}$ e de até $140 \mathrm{t} \mathrm{ha}^{-1}$ ano $^{-1}$ na linha do Equador.

\section{VANTAGENS E DESVANTAGENS DO EUCALIPTO}

O eucalipto não foi escolhido por mero acaso, principalmente no Brasil, como o gênero potencialmente mais apropriado para formação de florestas e produção de madeira, foi uma escolha, em função de inúmeras vantagens, destacadas por Bertola (2007): rápido crescimento volumétrico e potencialidade para produzir árvores com boa forma; características silviculturais desejáveis, como bom incremento, boa forma, facilidade a programas de manejo e melhoramento, tratos culturais, desbastes, desramas, etc; grande plasticidade do gênero, devido à grande diversidade de espécies, adaptando às mais diversas condições; elevada produção de sementes e facilidades de propagação vegetativa; adequação aos mais diferentes usos industriais, com ampla aceitação no mercado.

Segundo Pereira, Nova e Moreira (2004), o plantio de eucaliptos ajuda na captura e na retenção carbono, o qual se sabe, que é o componente do principal gás de estufa, o dióxido de carbono $\left(\mathrm{CO}_{2}\right)$.

Apesar nas vantagens do eucalipto sugeridas nos parágrafos anteriores, muito se tem questionado sobre a relação entre a cultura desta planta e o ressecamento e empobrecimento do solo.

Sobre o assunto, Bertola (2007), relata que para o completo esclarecimento dos motivos que levam ao ressecamento do solo, primeiramente seria necessário analisar se este fenômeno não seria resultado de alterações climáticas, e/ou da influência do homem.

Em relação ao empobrecimento do solo, Bertola (2007), descreve que quando comparado a qualquer outra cultura, o cultivo de eucalipto se mostra menos prejudicial ao ambiente devido aos seguintes motivos: cobertura vegetal conferindo 
maior proteção ao solo; maior ciclo de rotação, possibilitando o surgimento de outras plantas no interior dos plantios, formando o sub-bosque; menor necessidade de preparo do solo, devido ao longo período de rotação da cultura; menor utilização de fertilizantes; e maior tolerância da cultura ao ataque de pragas e doenças, acarretando menor necessidade de utilização de defensivos químicos.

\section{CARACTERIZAÇÃO DO CAPIM ELE- FANTE COMO FONTE DE BIOMASSA}

Segundo Shimoya et al. (2002) citando Deresz e Mozzer (1997) e Faria (1999), descrevem que o capim elefante é considerado uma das forrageiras mais importantes, e difundidas no país, visto que é uma gramínea de alto potencial de produção de matéria seca e grande eficiência fotossintética. Este capim se adapta muito bem às condições de clima $\mathrm{e}$ solo de praticamente todo o nosso país, pois se desenvolve bem ao nível do mar e em altitudes de até $2.200 \mathrm{~m}$.

De acordo com Andrade e Gomide (1972 apud DALL'AGNOL et al., 2004) o capim elefante atinge sua fase adulta em cerca de 20 semanas e, a partir desse momento, são observados pequenos acréscimos, com posterior estabilização e decréscimo na produção.

Respeitando-se técnicas adequadas para a cultura desta forrageira, a produção do capim elefante pode atingir até $300 \mathrm{t} / \mathrm{ha} / \mathrm{ano}$ de matéria verde (CARVALHO, 1985).

Em 1995, Silva, Faria e Corsi citado por Haddade et al. (2005), destacaram a alta produtividade da matéria seca, sendo descritos volumes anuais de até 80 toneladas por hectare.

\section{VANTAGENS E DESVANTAGENS DO CAPIM ELEFANTE}

O capim elefante (Pennisetum purpureum

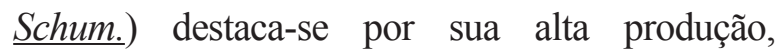
que faz dele uma das mais importantes forrageiras do mundo, pois congrega diferentes tipos de materiais genéticos, como híbridos interespecíficos, ecotipos, clones e variedades que ampliam consideravelmente sua área de adaptação ambiental, sendo capaz de resistir às condições climáticas desfavoráveis, como seca e frio (FREITAS et al., 2000; QUEIROZ FILHO, SILVA, NASCIMENTO, 2000; SANTOS, SILVA, QUEIROZ FILHO, 2001; SILVA et al., 2002).

Outra vantagem do capim elefante é que dado seu alto teor de fibra, que se apresenta com boas perspectivas como fonte energética. A energia da biomassa é a energia solar armazenada através do metabolismo da planta pela fotossíntese. Portanto, quanto maior for o crescimento da massa vegetal num menor período de tempo, mais eficiente será o aproveitamento da energia solar pela planta. Por isso as gramíneas forrageiras apresentam crescimento mais acelerado que outras fontes vegetais (AZEVEDO, 2000).

A biomassa seca do capim elefante pode gerar 25 unidades de energia para cada uma de origem fóssil consumida em sua produção. A cana-de-açúcar que até pouco tempo era líder em eficiência energética é capaz de alcançar somente nove unidades por cada uma consumida (OSAVA, 2007). Ainda, em relação ao balanço energético comparativo, Mazzarella (2006), ao citar Samson (1999) e Macedo et al. (2004) mostra as vantagens do capim elefante (tabela1):

TABELA 1 - Balanço energético comparativo entre o capim elefante e etanol

\begin{tabular}{lcc}
\hline & Capim elefante & Etanol \\
\hline Energia na produção agro & $0,791-0,668$ & $48.208-45.861$ \\
Energia na peletização & $0,480-0,480$ & $11.800-9.510$ \\
Energia gasta total & $1,271-1,148$ & $60.008-55.371$ \\
Energia produzida & $18,500-18,500$ & $499.400-565.700$ \\
Balanço energético & $14,6: 1-16,1: 1$ & $8,3: 1-10,2: 1$ \\
\hline
\end{tabular}

Fonte: Samson (1999) e Macedo et al (2004) apud Mazzarella (2006). 
O carvão em pellets é fabricado a partir de biomassas como o capim elefante. Sua principal vantagem sobre o carvão tradicional é que a matéria prima não precisa ter formatos definidos como são os carvões tradicionais, em forma de galhos ou pedaços (SISTEMA BRASILEIRO DE RESPOSTAS TÉCNICAS, 2008).

Os autores Paulino, Ferrari Junior e Andrade (2006) relatam que a cultura de capim elefante é favorável à proteção do meio ambiente, pois é altamente eficiente na fixação de $\mathrm{CO}_{2}$ (gás carbônico) atmosférico.

Em 2006, Mazzarella resumiu as vantagens do capim elefante: grande produtividade de massa seca/hectare/ano; menor extensão de área para uma dada produção; menor ciclo produtivo; melhor fluxo de caixa; possibilidade de mecanização; energético renovável; maior assimilação de carbono.

\section{ANÁLISES E DISCUSSÕES}

Segundo Chohfi e Valença (2009), o eucalipto e o capim elefante geram grande produtividade em material celulósico fibroso seco por ha/ano e devem ser utilizados no Brasil.

Fazendo um paralelo entre o eucalipto e o capim elefante, ambos classificados como biomassa produtora de energia, temse que o primeiro é classificado como um dendrocombustível (que pode ser produzido e obtido a partir de florestas plantadas ou nativas), e o segundo como um agrocombustível (tipicamente produzidos a partir de cultivos anuais) (NOGUEIRA; LORA, 2003).

O eucalipto é, ainda, aproveitado e cultivado para produção de lenha, estacas, moirões, dormentes, chapas de fibras e de partículas, fabricação de casas, móveis e estruturas (PEREIRA et al., 2000). Já o capim elefante, além do seu potencial como biomassa, tem sido considerado a forrageira mais utilizada nos sistemas de produção de leite (LOPES et al., 1997).

O solo, e o clima são fatores que influenciam diretamente na produção tanto do eucalipto, quanto do capim elefante. O clima brasileiro favorece a produção do eucalipto, proporcionando uma das mais altas taxas de produtividade na silvicultura, atingindo entre 40 e 50 metros cúbicos $\left(\mathrm{m}^{3}\right)$ de madeira por hectare ao ano, mais de 10 vezes superior à observada em países de clima temperado (OLIVEIRA JR, SEIXAS, 2006; RODRIGUEZ, BUENO, RODRIGUES, 1997). O mesmo ocorre com o capim elefante, espécie tipicamente tropical, mas que se apresenta capaz de tolerar temperaturas baixas antes de interromper o crescimento, sendo que alguns cultivares híbridos de capim elefante chegam a suportar temperaturas de $0^{\circ} \mathrm{C}$ (JACQUES, 1990 apud SEYE et al., 2000; MACOON, SOLLENBEERGER, MOORE, 2002).

O déficit hídrico não é capaz de comprometer o desenvolvimento de diversas espécies de eucalipto, possibilitando que os plantios sejam feitos na região dos cerrados, onde além do déficit hídrico, os solos apresentam baixa fertilidade (OLIVEIRA NETO et al., 2003).

O capim elefante, além de ser capaz de resistir às condições climáticas desfavoráveis, como seca e frio, ainda, se desenvolve em solos pobres e sem adubação (FREITAS et al., 2000; QUEIROZ FILHO, SILVA, NASCIMENTO, 2000; OLIVEIRA, 2005; SANTOS, SILVA, QUEIROZ FILHO, 2001; SILVA et al., 2002).

Uma das principiais características do capim elefante é sua alta produtividade, que de acordo com a Embrapa, é possível encontrar informações que descrevem a produtividade média do capim elefante, por ano, como de 60 toneladas de massa seca por hectare. O eucalipto, seu concorrente direto na produção de biomassa, gera apenas de 7,5 a 15 toneladas de massa seca por hectare 
(NOVA..., 2009).

Ainda, em comparação com o eucalipto, o capim elefante apresenta vantagens em relação ao tempo necessário para atingir o tamanho de corte. Enquanto o capim oferece duas a quatro colheitas anuais, devido ao rápido crescimento, o eucalipto necessita de seis anos para atingir um tamanho conveniente para o corte, e até sete anos se os valores econômicos forem considerados (OSAVA, 2007; RODRIGUEZ; BUENO; RODRIGUES, 1997).

Tanto o eucalipto quanto o capim elefante são utilizados não apenas para uso como fonte alternativa de energia através da queima direta e da gaseificação, mas também para a obtenção de carvão vegetal (BRITO et al., 1983; PAULINO, FERRARI JUNIOR, ANDRADE, 2006; URQUIAGA, ALVES, BODDEY, 2007).

Considerando-se os benefícios da produção do carvão pellets através do capim elefante tem-se a comparação com o eucalipto apresenta na tabela 2 :
TABELA 2. Carvão de eucalipto versus carvão de capim elefante

\begin{tabular}{ccc}
\hline & Capim elefante & Eucalipto \\
\hline Tonelada/hectare/ano & 38 & 09 \\
Primeira colheita & $120-150$ dias & $6-7$ anos \\
Intervalos de corte & $70-120$ dias & $6-7$ anos \\
Mananciais & Conservador & Inibidor \\
$\begin{array}{c}\text { Compatibilidade animal } \\
\text { na plantação }\end{array}$ & Compatível & Não \\
compatível
\end{tabular}

Fonte: Sistema Brasileiro de Respostas Técnicas (2008)

A produção de energia alternativa é um dos objetivos prioritários do mundo atual. Neste quesito o capim elefante apresenta-se, mais eficaz que o eucalipto, visto que é capaz de produzir 189.000.000 ha/ano kcal, enquanto o eucalipto produz $92.820 .000 \mathrm{ha} /$ ano kcal. Além disso, quando se utiliza a biomassa do capim elefante fonte exclusiva de energia, há uma redução de $100 \%$ no custo de produção, quando comparado com o eucalipto (VILELA; CERIZE, 2008).

TABELA 3. Resultados das avaliações financeiras da lenha de eucalipto e da biomassa de capim elefante

\begin{tabular}{|c|c|c|c|c|c|c|c|}
\hline \multirow{2}{*}{ Tratamentos } & \multicolumn{2}{|c|}{ Lenha de Eucalipto } & \multicolumn{2}{|c|}{ Biomassa } & \multirow{2}{*}{$\begin{array}{l}\text { Custo } \\
\text { total } \\
(\mathrm{R} \$)\end{array}$} & \multirow{2}{*}{$\begin{array}{l}\text { Custo } \\
\text { produção } \\
\text { (t) }\end{array}$} & \multirow{2}{*}{$\begin{array}{c}\text { Custo/t } \\
\text { (R\$) }\end{array}$} \\
\hline & Consumo (st) & Custo (R\$) & Consumo (m) & Custo (R\$) & & & \\
\hline $\begin{array}{c}50 \% \text { biomassa } x \\
50 \% \text { Lenha }\end{array}$ & 9,21 & 396,03 & 10,80 & 97,42 & 493,45 & 33 & 14,95 \\
\hline $\begin{array}{c}66 \% \text { biomassa } x \\
33 \% \text { Lenha }\end{array}$ & 4,50 & 193,50 & 16,90 & 152,44 & 345,94 & 30,66 & 11,28 \\
\hline $100 \%$ biomassa & ------- & ------- & 24,57 & 221,62 & 221,62 & 28 & 7,92 \\
\hline $\begin{array}{l}100 \% \\
\text { Lenha } \\
\end{array}$ & 10,20 & 438,60 & ------- & ------- & 438,60 & 24 & 18,28 \\
\hline
\end{tabular}

Fonte: Vilela e Cerize (2008).

De acordo com os valores descritos acima, comprova-se a superioridade do uso do capim elefante em comparação ao eucalipto como fonte energética. Em uma área de um hectare de eucalipto tem-se o seguinte resultado: $60 \mathrm{t} / \mathrm{ha} /$ ano de massa seca $=92,82 \times 10^{6} \mathrm{kcal}$, portanto 1 $\mathbf{t}=\mathbf{1 , 5 5} \times 10^{6} \mathrm{kcal}$, para a mesma área de capim elefante tem-se $80 \mathrm{t} / \mathrm{ha} / \mathrm{ano}$ de massa seca $=$
$189,0 \times 10^{6} \mathrm{kcal}$, portanto $\mathbf{1} \mathbf{t}=\mathbf{2 , 3 6} \times \mathbf{1 0}^{6} \mathrm{kcal}$.

Finalizando esta discussão tem-se a questão ambiental, tão evidenciada na atualidade. O plantio de eucaliptos é importante para o meio ambiente, visto que ajuda na captura e na retenção de carbono, o qual se sabe que é o componente do principal gás de estufa, o dióxido de carbono $\left(\mathrm{CO}_{2}\right)$. No entanto, a produção do capim elefante 
é, ainda, mais favorável, devido a sua alta eficiência na fixação de $\mathrm{CO}_{2}$ durante o processo de fotossíntese. Esta característica é típica de gramíneas tropicais que crescem rapidamente, aperfeiçoam o uso da água do solo e da energia solar para a produção de biomassa vegetal (PAULINO; FERRARI JUNIOR; ANDRADE, 2006; PEREIRA; NOVA; MOREIRA, 2004).

\section{CONCLUSÕES}

No decorrer desse trabalho conceituouse biomassa energética como toda a matéria orgânica capaz de ser queimada, decomposta ou reciclada, gerar alguma forma de energia, direta ou indiretamente. Vale ressaltar que, além de ser uma fonte de energia renovável, outra vantagem da utilização da biomassa em substituição aos combustíveis fósseis é o fato desta gerar uma menor poluição atmosfera global e localizada, estabilidade do ciclo de carbono e gerar grande quantidade de empregos.

Ao final desta revisão verificou-se que o capim elefante apresenta diversas vantagens em relação ao eucalipto: maior produtividade de massa seca/hectare/ano; menor extensão de área para uma dada produção; menor ciclo produtivo; melhor fluxo de caixa; possibilidade de mecanização; energético renovável; grande assimilação de carbono e maior produção energética.

Assim, diante dos dados teóricos expostos neste artigo, verificou-se que o capim elefante é mais eficiente e viável do que o eucalipto na produção de energia.

\section{REFERÊNCIAS}

ANDERSON, G. Q. A.; FERGUSSON, M. J. Energy from biomass in the UK: sources, processes and biodiversity implications. Ibis. v. 148, p. 180183, 2006.

AZEVEDO, P. B. M. Aspecto econômico da produção agrícola do capim-elefante. In: Encontro de Energia no Meio Rural, 2000. Anais do Encontro de Energia no Meio Rural.
BERTOLA, A. Eucalipto - 100 anos de Brasil. Disponível em: $<$ http.//www.celuloseonline.com. br/imagembank/Docs/DocBank/dc/dc022.pdf >. Acesso em: 05 ago. 2007.

BRITO, J. O;BARRICHELO, L. E. G. Correlações entre características físicas e químicas da madeira e a produção de carvão vegetal: I. densidade e teor de lignina da madeira de eucalipto. IPEF, n. 14, p. 9-20, 1977.

BRITO, J. O. et al. Análise da Produção Energética e de Carvão Vegetal de Espécies de Eucalipto. IPEF, n. 23, p. 53-56, 1983.

BUBU, A. Biomassa: uma energia brasileira. Revista Eco 21. Rio de Janeiro, v. 93, n. 8, ago. 2004.

CARVALHO, M. M. et al. Capim-elefante produção e utilização, Brasília: Embrapa-SPI, 1997.

CHOHFI, F. M.; VALENÇA, G. P. Novos produtos e energia a partir da biomassa, uma matéria prima abundante e renovável para o Brasil. Revista Agrogeoambiental, Inconfidentes, v. 1, n. 1, p. 8090, 2009.

CATHARINO, E. L. Eucalipto. Disponível em: <http://www.cotianet.com.br/jornalatuante/ mat027.htm>. Acesso em 19 ago. 2007.

DALL AGNOL, et al. Produção de forragem de capim-elefante sob clima frio. Curva de crescimento e valor nutritivo. Revista Brasileira de Zootecnia, v. 33, n. 5, p. 1110-1117, 2004.

FREITAS, N. S. et al. Caracterização e diversidade genética do capim-elefante e seus híbridos com milheto mediante padrões isoenzimáticos. Pesq. Agropec. Bras., Brasília, v. 35, n. 6, p. 1125-1133, jun. 2000.

GUARDABASSI, P. M. Sustentabilidade da biomassa como fonte de energia perspectivas 
para paises em desenvolvimento. 2006. 123 f. Dissertação de Mestrado em Energia - Programa Interunidades de Pós-Graduação em Energia, Faculdade de Economia e Administração da Universidade de São Paulo, São Paulo, 2006.

GRAUER, A.; KAWANO, M. Uso da biomassa para a produção de energia. Disponível em: $<$ http://www.ecovale.org.br/noticias023.php $>$. Acesso em: 09/10/ 2007.

HADDADE. I. R. etal. Morfogênese e estruturação vegetativa em quatro genótipos de capim-elefante (Pennisetum purpureum schum.). Arq. Bras. Med. Vet. Zootec., v. 57, n. 6, p. 811-819, 2005.

KRONKA, F. J. N. et al. Mapeamento e quantificação do reflorestamento no Estado de São Paulo. Florestation Inventory, v. 6, n. 14, jan. 2003.

LANDIM, A. B. et al. Sistema de recuperação de biomassa. Revista da Madeira. Curitiba, v.17, n.104, abr. 2007.

LOPES, etal. Avaliação qualitativa de dois métodos de amostragem em pastagens de capim-elefante (Pennisetum purpureum Schum.). Posturas tropicales. Cali, v. 19, n. 3, p. 36-41, 1997.

MACOON, B.; SOLLENBERGER, L, E.; MOORE, J. E. Forages and pasture management Defoliation effects on persistence and productivity of four pennisetum spp. Genotypes, Agronomy Journal, v. 94, May/June, 2002.

MAZZARELLA, V. Capim-elefante como fonte de biomassa para a siderugia.ppt. 2006. Disponível em: <www.abmbrasil.com.br/cim/ download/10h45\%20Mazzarela.pps $>$. Acesso em: 17 de maio de 2008 .

\section{MINISTÉIRO DE MINAS E ENERGIA.} Balanço energético nacional 2005, ano base 2004. Disponível: <http://www.mme. gov.br/site/menu/select_main_menu_item. do? channelId $=1432$ \&pageId $=4060>$. Acesso em: 15/08/2007.

NOGUEIRA, L. A. H.; LORA, E. S. Dendroenergia: fundamentos e aplicações. 2. ed. Rio de Janeiro: Interciência, 2003.

NOVA fonte de energia. Disponível em: $<$ http://www.inda.org.br/revista_materia. php?Codigo=82>. Acesso em: 17 de set. 2009.

OLIVEIRA, E. Capim que vira carvão, 2005. Disponível em: <http://www.cvrdint. com/saladeimprensa/pt/agencia_vale/noticia. asp?id=14464>. Acesso em: 17 de maio de 2008.

OLIVEIRA JUNIOR, E. D.; SEIXAS, F. Análise energética de dois sistemas mecanizados na colheita do eucalipto. Scientia Forestalis, n. 70, p. 49-57, abr. 2006.

OLIVEIRA NETO, S. N. et al. Produção e distribuição de biomassa em eucalyptus camaldulensis Dehn. Em florestas à adubação e ao espaçamento. Revista Árvore, Viçosa, v. 27, n. 1, p. 15-23, 2003.

OSAVA, M. Capim-elefante, novo campeão em biomassa no Brasil. Envolverde: Revista Digital de Meio Ambiente e Desenvolvimento. 2007. Disponível em: < http://envolverde.ig.com.br/?P HPSESSID $=$ fb 1763c5abc0b02cb940a4edaad7e0 f9\&busca $=$ capim+elefante $\#>$. Acesso em: 15 de maio de 2008.

PAULINO, V. T.; FERRARI JUNIOR, E.; ANDRADE, J. B. Capim-elefante: Uma fonte alternativa promissora para a produção de energia. Disponível em: <http.//www.iz.sp.gov.br/ artigos/documentos/valdinei evaldojoaoelefantesiderurgialjun2006.pdf $>$. Acesso: 25 mar. 2007.

PEREIRA, A. B.; NOVA, N. A.L.; MOREIRA, P.R. Modelo para avaliação da produção de matéria 
seca de fustes de eucalyptus grandis em função da densidade de plantio, tempo de ciclo e energia solar disponível. Acta Scientiarum Agronomy, Maringá, v.26, n. 4, p. 437-441, 2004.

PEREIRA, J. C. D et al. Características da Madeira de algumas espécies de eucalipto plantadas no Brasil. Embrapa Florestas, Colombo, documento 38, 2000.

QUESADA, D. M. et al. Parâmetros qualitativos de genótipos de capim-elefante (Pennisetum purpureum schum.) estudados para a produção de energia através da biomassa. Seropédica, Rio de Janeiro, nov., 2004.

RODRIGUEZ, L. C. E.; BUENO, A. R. S; RODRIGUES, F. Rotações de eucaliptos mais longas: Análise volumétrica e econômica. Scientia Forestalis, n. 51, p. 15-28, jun. 1997.

ROSTAND, R. Biomassa: a energia da vida. Disponível em: <http://www.aondevamos. eng.br/textos/texto09.htm>. Acesso em: $15 / 01 / 2007$.

SALOMON, K. R. N 5 Energia de biomassa. Apostila utilizada no curso de especialização em Uso Racional de Energia da Universidade Federal de Itajubá, 2007.

SANTOS, E. A.; SILVA, D.S.; QUEIROZ FILHO, J. L. Aspectos produtivos do capimelefante (Pennisetum purpureum, schum.) cv. Roxo no brejo paraibano. Revista Brasileira de Zootecnia, v. 30, n. 1, p. 31-36, 2001.

SANTOS, E. A.; SILVA, D.S.; QUEIROZ FILHO, J. L. Perfilhamento e algumas características morfológicas do capim-elefante cv. Roxo sob quatro alturas de corte em duas épocas do ano. Revista Brasileira de Zootecnia, v. 30 n. 1, p. 2430, 2001.

SEYE, O. et al. Queima direta de gramínea projeto integrado de biomassa - PIB. In: Encontro de
Energia no Meio Rural, 2000. Anais do Encontro de Energia no Meio Rural.

SHIMOYA, A. et al. Repetibilidade de características forrageiras do capim-elefante. Scientia Agrícola, v. 59, n.2, p. 227-234, abr./jun. 2002.

SILVA, J. N.; CARDOSO SOBRINHO, J.; SAIKI, E. T. Utilização de biomassa na secagem de produtos agrícolas via gaseificação com combustão adjacente dos gases produzidos. Eng. Agric., Jaboticabal, v. 24, n. 2, p. 405-411, maio/ ago. 2004.

SILVA, M.M. P. etal. Composição bromatológica, disponibilidade de forragem e índice de área foliar de 17 genótipos de capim-elefante (Pennisetum purpureum schum.) sob pastejo, em Campos dos Goytacazes, RJ. Revista Brasileira de Zootecnia, v. 31, n. 1, p. 313-320, 2002.

SISTEMA BRASILEIRO DE RESPOSTAS TÉCNICAS. Produção de carvão vegetal. Disponível em: <http://209.85.165.104/sear ch?q=cache:GlvYFfQ1rV0J:sbrtv1.ibict.br/ upload/sbrt3081.pdf\%3FPHPSESSID\%3D 0905ca2b4823656be062b5d86fd6b4c8+SIS TEMA+BRASILEIRO+DE+RESPOSTAS $+\mathrm{T} \% \mathrm{C} 3 \% 89 \mathrm{CNICAS} .+$ Produ $\% \mathrm{C} 3 \% \mathrm{~A} 7 \% \mathrm{C}$ $3 \% \mathrm{~A} 3 \mathrm{o}+\mathrm{de}+$ carv $\% \mathrm{C} 3 \% \mathrm{~A} 3 \mathrm{o}+$ vegetal.\&hl $=\mathrm{p}-$ $\mathrm{t}$-BR\&ct $=$ clnk\&cd $=1 \& \mathrm{gl}=\mathrm{br}>$. Acesso em $15 \mathrm{de}$ maio de 2008.

URQUIAGA; ALVES, B.; BODDEY, R. Capim-elefante: uma fonte alternativa de energia. Disponível em: $<\mathrm{http}$.//www.infobios. com/artigos/2006-2capimelefante/index,html $>$. Acesso em: 15 mar. 2007.

VILELA, H; CERIZE, D. Capim-elefante paraíso na geração de energia. Portal Agronomia. Disponível em: <http://www.agronomia.com. br/conteudo/artigos/artigos_capim_elefante_ paraiso_geracao_energia.htm $>$. Acesso: 06 de julho de 2008. 